\title{
Evaluation of Cashew Nut Shell Liquid Borate Ester as Pour Point Depressant for Flow Assurance of Waxy Crude Oil
}

\author{
William Iheanyi Eke 1,*(D), Sampson Kofi Kyei 2(D), Ozioma Achugasim 3(D), Joseph Ajienka 4(D), \\ Onyewuchi Akaranta 1,3 iD
}

1 World Bank-Africa Centre of Excellence for Oilfield Chemicals Research, University of Port Harcourt, Port Harcourt, Nigeria; $\quad$ william_eke@uniport.edu.ng $\quad$ (W.I.E.), $\quad$ eke.iheanyi@aceuniport.org $\quad$ (W.I.E), onyewuchi.akaranta@uniport.edu.ng (O.A);

2 Department of Chemical Engineering, Kumasi Technical University, Kumasi, Ghana; Sampson.kyei@kstu.edu.gh (S.K.K.);

3 Department of Pure \& Industrial Chemistry, University of Port Harcourt, Port Harcourt, Nigeria; ozioma.achugasim@uniport.edu.ng (O.A.);

4 Department of Petroleum Engineering, University of Port Harcourt, Port Harcourt, Nigeria; joseph.ajienka@uniport.edu.ng (J.A.);

* Correspondence: eke.iheanyi@aceuniport.org (W.I.E.);

Received: 17.05.2021; Revised: 20.07.2021; Accepted: 25.07.2021; Published: 6.09.2021

\begin{abstract}
The development of chemical solutions to wax problems by modifying renewable natural products is an innovative response to the need for cheaper, eco-friendly pour point depressants for waxy crude oil flow improvement. Natural cashew-nut shell liquid (CNSL) was extracted from shells of Anacardium occidentale and derivatized into the borate ester. Pour point of oil doped with 500ppm CNSL borate ester was reduced by $-24^{\circ} \mathrm{C}$. The effect of borate ester addition on wax morphology was studied by cross-polarized microscopy. Analysis of micrographs using ImageJ software showed a decrease in Feret diameter, aspect ratio, and boundary fractal dimension of wax crystals in doped oil and increased crystal circularity and solidity, indicating the evolution of smaller, rounder, regular structures with smoother, even surfaces. At $10^{\circ} \mathrm{C}$, oil shear stress and dynamic viscosity were reduced by $27.6 \%$ and $24.6 \%$, respectively. Pour point depressant and flow improvement effects of additive were related to changes in crystal morphology.
\end{abstract}

Keywords: cashew nut shell liquid; borate ester; waxy crude oil; pour point depressant; flow improver; wax crystal morphology.

(C) 2021 by the authors. This article is an open-access article distributed under the terms and conditions of the Creative Commons Attribution (CC BY) license (https://creativecommons.org/licenses/by/4.0/).

\section{Introduction}

Wax precipitation and deposition are long-standing problems in producing, transporting, and storing paraffinic crude oil. Waxy crude oils usually exhibit high pour points and are difficult to handle at low temperatures $[1,2]$. This is because long-chain paraffin (> $\mathrm{C}_{16}$ ) crystallizes from crude oil due to loss of solubility with decreasing temperature below the wax appearance temperature (WAT) of the oil, resulting in non-newtonian flow behavior and high oil viscosity [3]. Wax crystals form large, three-dimensional, volume-spanning networks in oil, a process which under static conditions results in gelation of oil in the pipeline leading to restart ability issues. In addition, the deposition of wax on pipe walls constricts tubings and 
pipelines $[2,4,5]$. These outcomes have serious cost implications arising from additional energy requirements to pump oil as it becomes more viscous, reduction in capacity utilization, and expenses incurred on repairs/replacement of damaged equipment and wax remedial operations [6].

The wax formation can be mitigated by heating, thermal insulation of pipelines, and injection of chemical additives [7-9]. Due to the relative simplicity of application, efficiency, and cost-effectiveness, the use of chemical additives for the control of wax is a widely adopted technique [10]. Wax formation in crude oil proceeds via nucleation, crystal growth and agglomeration, leading to poor oil flow ability [11]. Pour point depressants (PPDs) are chemical compounds that interact with crude oil paraffin in a manner that disrupts the growth and aggregation of the wax crystal, thus hindering the formation of a large wax network such that the oil can still pour at low temperatures [12]. Generally, the structure of pour point depressants consists of a hydrophobic segment similar to waxes and a dissimilar polar segment that alters the wax crystal habit. Wax-PPD interactions occur via several mechanisms such as nucleation, adsorption, co-crystallization, dispersion, and solubilization [13].

Pour point depressant chemistry is dominated by polymeric compounds, notably poly (ethylene-co-vinylacetate), poly (alkyl acrylate/ methacrylate), poly (alkyl maleate/ fumarateco- $\alpha$-olefin), and poly (styrene alkyl maleimide/maleate) [13]. However, due to the high cost and selectivity of PPDs to crude oil, natural products obtained from plants have become attractive as cheaper, renewable, and more eco-sustainable alternatives. Several reports have shown that natural plant surfactants, pristine plant seed oils, and their derivatives are effective pour point depressants, wax inhibitors, and flow improvers for waxy crude oils [14-20]. Depression in pour point and improvement in oil flow properties have also been reported in waxy crude oils treated with derivatives of cardanol and pristine and derivatized natural cashew nut shell liquid extracted from Anacardium Occidentale shell biomass - an agricultural waste [21-24]. Cashew nut shell liquid (CNSL) is a by-product of the cashew industry and a renewable chemical feedstock. It is a rich source of phenolic lipids composed of a family of structurally related alkyl/alkenylphenols: anacardic acid, cardol, cardanol and 2-methyl cardol $[25,26]$. Natural CNSL-based pour point depressants were previously developed by modifying CNSL with glycols and alcoholamines [24, 27-29].

This paper further advances this concept. It reports developing a new bio-based flow improver using inexpensive materials: natural cashew nut shell liquid (which contains mainly anacardic acid) and boric acid. The cashew nut-shell liquid-borate ester formulation was evaluated as a PPD for Niger-Delta waxy crude oil. The effect of the borate ester on wax crystal morphology and oil flowability was studied by cross-polarized microscopy and viscometric analysis, respectively.

\section{Materials and Methods}

\subsection{Materials.}

Boric acid (BDH chemicals); methanol, n-heptane, petroleum benzine, dichloromethane, toluene, xylene (Sigma-Aldrich); acetone; waxy crude oil (sampled at the wellhead). 


\subsection{Extraction of cashew nut shell liquid.}

Macerated cashew nut-shell (CNS) was extracted with acetone according to the literature [23]. CNSL was concentrated, and the solvent was recovered in vacuo using a rotary evaporator.

\subsection{Crude oil characterization.}

2.3.1. Specific gravity/ API gravity \& Kinematic viscosity.

Crude oil specific gravity and API gravity were determined by the hydrometer method according to ASTM D 1298-12b. Stanhope-Seta KV-8 Viscometer bath was used to determine kinematic viscosity of crude oil sample at $40^{\circ} \mathrm{C}$ and $100^{\circ} \mathrm{C}$ according to the standard test method for kinematic viscosity of transparent and opaque liquids and calculation of dynamic viscosity (ASTM D455-12).

\subsubsection{Water content.}

Determination of water content was carried out by Dean-Stark distillation (ASTM D 4006-11). An equal volume of crude oil and xylene were mixed and refluxed for 1 hour. The water evolved was collected in a Dean-Stark trap, and crude oil-water content was calculated.

\subsubsection{Wax content.}

The acetone method (UOP 46-64) was adopted for crude oil wax content determination. The method was modified by eliminating the oil clarification step. $5 \mathrm{~g}$ of crude oil was dissolved in $50 \mathrm{ml}$ of toluene. The solvent was evaporated. The residue was dissolved in $100 \mathrm{ml}$ petroleum benzine/acetone mixture $(3: 1)$, stored in deep freeze $\left(-20^{\circ} \mathrm{C}\right)$ for 2 hours, filtered with a preweighed filter paper, and dried. The mass of wax precipitate was obtained by difference, and the percentage wax content was calculated based on the original oil mass.

\subsubsection{WAT \& pour point.}

Wax appearance temperature was determined according to the standard test method for cloud point of petroleum products (linear cooling rate method) (ASTM D5772) using an Olympus BX51 cross-polarized microscope. The procedure is outlined in 2.5.2 Pour point was determined by ASTM D5853-17a - Standard Test Method for Pour Point of Crude Oils (Procedure A) using a Stanhope-Seta cloud \& pour point refrigerator (93531-7). The procedure is outlined in 2.5.1

\subsubsection{Asphaltene content.}

Asphaltene content (n-heptane insoluble) was determined by refluxing $3 \mathrm{~g}$ of crude oil in $90 \mathrm{ml}$ of heptane for $1 \mathrm{hr}$. The solution was allowed to cool and then vacuum-filtered using a $0.45 \mu \mathrm{m}$ Millipore ${ }^{\circledR}$ filter paper.

\subsubsection{Saturates, aromatics resins and asphaltenes (SARA) analysis.}

Crude oil was first deasphalted by refluxing with n-heptane. The saturates, aromatics, and resin components of deasphalted crude oil (maltenes) were separated on a silica gel column 
by elution with petroleum benzine, toluene, and 3:1 dichloromethane: methanol mixture, respectively.

\subsubsection{Chromatographic analysis of crude oil and wax precipitate.}

Paraffin carbon number distribution of the oil sample and the wax precipitate was determined by gas chromatography (GC) (ASTM D3328). A total of $1 \mu 1$ of crude oil sample was auto-injected into the chromatograph (Agilent 7890A) equipped with a flame ionization detector (FID). The temperature and pressure of the inlet were maintained at $250^{\circ} \mathrm{C}$ and $18.54 \mathrm{psi}$, respectively. The carrier gas and sample flow rates were $0.455 \mathrm{ml} / \mathrm{min}$ and $15.0 \mathrm{~cm} / \mathrm{sec}$, respectively. The capillary column, $50 \mathrm{~m}$ long with an internal diameter of $0.2 \mathrm{~mm}$ and a film thickness of $0.5 \mu \mathrm{m}$, was maintained at $325^{\circ} \mathrm{C}$.

The wax fraction of the crude oil was obtained by the modified UOP 46-64 method. The dried wax precipitate was re-dissolved in warm dichloromethane (DCM) before GC analysis. The wax precipitate was analyzed in the same manner as the crude oil.

\subsection{Preparation of CNSL borate ester.}

Natural CNSL $(250 \mathrm{ml})$ was mixed in a three-necked flask with $14.8 \mathrm{~g}$ of boric acid (representing a mole ratio of $3: 1$ ) and $40 \mathrm{ml}$ of xylene. The mixture was heated at $95-115^{\circ} \mathrm{C}$ with continuous stirring for 2 hours. Sulfamic acid was used as a catalyst., The water of esterification was collected in a Dean-Stark trap as an azeotrope with xylene. The product was a viscous brick-red liquid. The derivative, natural CNSL, and boric acid spectra were recorded with a Fourier transform infrared spectrophotometer. The additive for evaluation was formulated by diluting the derivative with xylene to obtain a $75 \%(\mathrm{v} / \mathrm{v})$ solution of borate ester in xylene.

\subsection{Evaluation of CNSL borate ester.}

\subsubsection{Pourpoint.}

A total of $40 \mathrm{ml}$ of crude oil, warmed to $60^{\circ} \mathrm{C}$ using a water bath, was poured into the pour point test jar to reach the mark and doped with additive formulation at concentrations of 250, 500, 1000, and 2000ppm. The jar was corked, thermometer and rubber gasket were inserted. The sample was placed in the cooling chamber of the Stanhope-Seta cloud point \& pour point refrigerator. The sample was removed from the cooling chamber and observed for flow every $3^{\circ} \mathrm{C}$ decrease in temperature in line ASTM D5853-17a.

\subsubsection{Optical microscopy studies.}

The effect of the additives on wax crystal morphology and microstructure was studied by polarized optical microscopy using an Olympus BX51 cross-polarized microscope. The crude oil was warmed to $60^{\circ} \mathrm{C}$ and doped with the additive. An aliquot of doped oil was transferred to a quartz sample holder and placed in the sample chamber of the Linkam THMS 600 temperature-controlled stage. The experiment was automatically regulated with Linksys 32 software and T95-linkpad system controller. The sample was heated to $60^{\circ} \mathrm{C}$ at $5^{\circ} \mathrm{C} / \mathrm{min}$, a hold time of $1 \mathrm{~min}$ was observed before commencement of the cooling cycle. The cooling cycle commenced by the simultaneous circulation of liquid nitrogen and water via LNP95 liquid nitrogen pump and ECP water pump, respectively. Cooling was done at the rate of $1^{\circ} \mathrm{C} / \mathrm{min}$ 
and terminated at $10^{\circ} \mathrm{C}$. The wax crystallization process was monitored on the live computer feed, and still, images were captured automatically every 30seconds. The micrographs were processed and analyzed using ImageJ software. Wax crystals were characterized using four morphological and micro-structural parameters: aspect ratio, circularity, solidity, and boundary fractal dimension. Boundary fractal dimension was determined by the box-counting method using box sizes of 2, 3,4,6,8,12,16,32, and 64 .

\subsubsection{Viscometric analysis.}

Viscometric analysis was carried out using a coaxial cylinder rotational viscometer (Ofite 900). The oil sample was warmed to a temperature of $60^{\circ} \mathrm{C}$, doped with the CNSL-borate ester formulation, and transferred to the viscometer cup. The shear stress and viscosity of the oil were measured between 10-100rpm (corresponding to shear rates of $17.02 \mathrm{~s}^{-1}-170.23 \mathrm{~s}^{-1}$ ), at $5^{\circ} \mathrm{C}$ temperature intervals from $50^{\circ} \mathrm{C}-10^{\circ} \mathrm{C}$.

\section{Results and Discussion}

\subsection{Crude oil characterization.}

The crude oil is medium gravity waxy oil with high saturates content and moderate wax content (Table 1). Its tendency towards wax instability is evident in the SARA composition. Crude oil in which the proportion of these molecular group types is in the order: saturates > aromatics > resins > asphaltenes are prone to wax instability, especially if the saturates fraction is dominated by high molecular weight paraffin [30]. The chromatograms of the crude oil and its wax precipitate are presented in (Fig. 1). The n-paraffin carbon number distribution shows that $\mathrm{C}_{20+}$ paraffin is abundant in the oil, with a modal paraffin carbon number of $\mathrm{C}_{25}$ (Fig. 2).

Table 1. Physico-chemical and compositional properties of crude oil.

\begin{tabular}{l|l} 
Properties & Crude oil \\
\hline Specific gravity & 0.887 \\
\hline API gravity & 28 \\
\hline Pour point $\left({ }^{\circ} \mathrm{C}\right)$ & 21 \\
\hline WAT $\left({ }^{\circ} \mathrm{C}\right)$ & 33.6 \\
\hline Kinematic viscosity, cSt $\left(40^{\circ} \mathrm{C}\right)$ & 9.96 \\
\hline Kinematic viscosity, cSt $\left(100^{\circ} \mathrm{C}\right)$ & 2.67 \\
\hline Water content $(\%)$ & 0.025 \\
\hline Wax content $(\%)$ & 9.3 \\
\hline Saturate $(\%)$ & 59.7 \\
\hline Aromatics $(\%)$ & 34.9 \\
\hline Resins $(\%)$ & 4.00 \\
\hline Asphaltene content $(\%)$ & 0.40
\end{tabular}

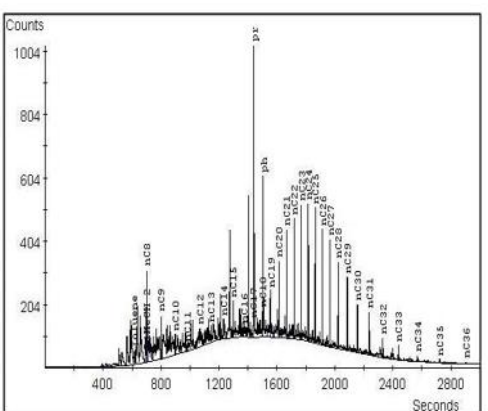

(a)

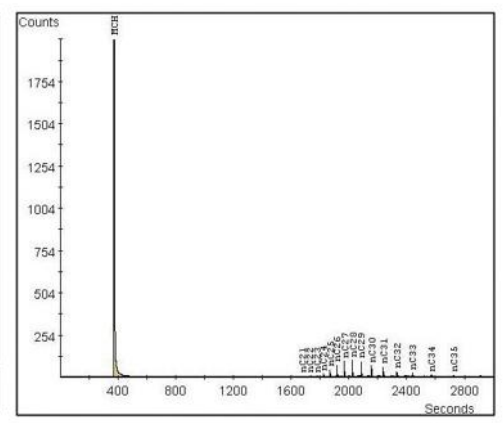

(b)

Figure 1. Chromatogram of crude oil (a); wax precipitate from crude oil (b). 


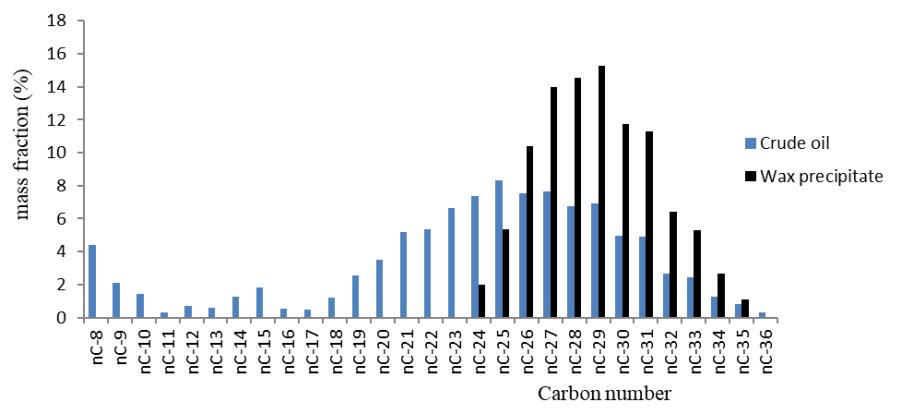

Figure 2. Paraffin carbon number distribution of crude oil and wax precipitate.

The abundance of these large n-paraffins in oil increases the tendency for wax crystallization [6, 31]. Also, $n-\mathrm{C}_{24+}$ paraffin is deleterious to the performance of pour point depressants and, at high concentration, may result in oil resistance to PPD treatment [31]. Relative to the crude oil, a shift is observed in the modal paraffin carbon number of the wax precipitate from $\mathrm{C}_{25}$ to $\mathrm{C}_{29}$ (Fig. 2).

In addition, the smallest $n$-alkane to crystallize appreciably was $\mathrm{C}_{24}$ (trace amounts of $n-C_{21}-n-C_{23}$ exist in the wax deposit). This is indicative of the preferential crystallization of larger n-paraffins from oil. The higher molecular weight paraffin distribution in wax precipitate in relation to the oil reflects the extent of crystallization of individual n-alkanes relative to other members. It has been shown that such a distribution is not simply a function of the composition of the wax fraction but of the totality of interactions between the crystallizable n-paraffins and other non-paraffinic heavy organics in the oil $[32,33]$. As oil is cooled, the longer n-alkanes crystallize first as their solubility limit is exceeded due to their higher molecular weight [34]. The wax deposit has an average carbon number of 27 , which is within the range of values reported for some waxes [35]. The crystallization of $n-C_{24+}$ paraffin is primarily responsible for the high dynamic viscosity of the oil at low temperature and ease of oil gelation under static conditions.

\subsection{Extraction of CNSL and preparation of cashew nut shell liquid borate ester.}

CNSL extracted using low-boiling solvents is a mixture of alkyl/alkenylphenols consisting of $65-90 \%$ anacardic acid [25, 36-38].

The FTIR spectra of cashew nut shell liquid borate ester, boric acid, and natural cashew nut shell liquid are shown in Fig. 3. The band at $3418.0 \mathrm{~cm}^{-1}$ in the spectrum of the borate ester is due to the $\mathrm{O}-\mathrm{H}$ vibration of the carboxylic acid group of natural CNSL (anacardic acid). The shift of the derivative's $\mathrm{O}-\mathrm{H}$ band towards higher frequency and the increase in transmittance value relative to natural CNSL indicates the diminution of phenolic $\mathrm{O}-\mathrm{H}$ groups in the derivative, which have been used in borate ester bond formation. New bands characteristic of borate ester appears in the derivative at $1394.0 \mathrm{~cm}^{-1}$ and $1118.2 \mathrm{~cm}^{-1}[39,40]$. These bands are the borate ester $\mathrm{B}-\mathrm{O}$ and $\mathrm{C}-\mathrm{O}$ stretching vibrations, respectively, indicating the formation of borate ester linkages between boric acid and CNSL alkylphenols [40]. The band at 3011.7 $\mathrm{cm}^{-1}$ is the $=\mathrm{C}-\mathrm{H}$ stretching vibration of alkene from the 15-carbon aliphatic chain of CNSL. The $=\mathrm{C}-\mathrm{H}$ deformation (bending) vibrations at $708.2 \mathrm{~cm}^{-1}$ confirm the stretching vibration. Similarly, the vibrations at $2922.0 \mathrm{~cm}^{-1}$ and $2855.1 \mathrm{~cm}^{-1}$ are due to $\mathrm{C}-\mathrm{H}$ vibrations of methylene and methyl groups of the hydrocarbon chain, which are confirmed by deformation vibrations of methyl $\mathrm{C}-\mathrm{H}$ at $1479.8 \mathrm{~cm}^{-1}$. Aromatic $\mathrm{C}=\mathrm{C}$ vibrations of the benzene ring give rise to the intense band at $1602.8 \mathrm{~cm}^{-1}$. 


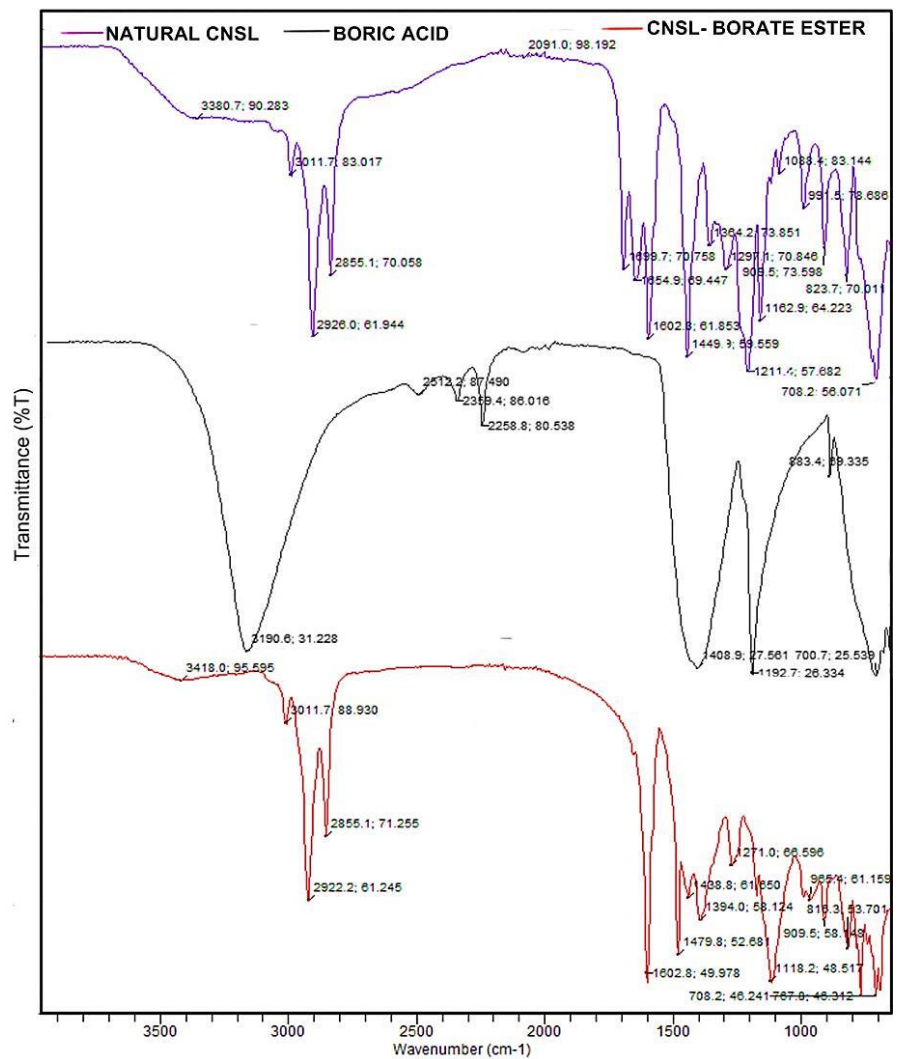

Figure 3. FTIR spectra of natural CNSL, boric acid, and CNSL-borate ester.

\subsection{Performance evaluation of CNSL borate ester.}

\subsubsection{Effect on crude oil pour point.}

The effect of additive dosage on the crude oil pour point is shown in Table 2. The pour point depressant effect was dependent on dosage such that the crude oil pours point was reduced up to the optimal dosage of 500ppm, beyond which the pour point depressant effect was reversed. A maximum pour point depression of $-24^{\circ} \mathrm{C}$ was achieved. The steady increase observed in crude oil pours point at additive concentrations above the optimal dosage suggests that excessive concentration of the additive molecules in oil counteracts the pour point depressant mechanism.

Table 2. Effect of additive dosage on crude oil pour point.

\begin{tabular}{c|l|l|l|l|l|l} 
Dosage $(\mathrm{ppm})$ & 0 & 250 & 500 & 1000 & 2000 \\
\hline Pour point $\left({ }^{\circ} \mathrm{C}\right)$ & & 21 & 3 & -3 & 3 & 18
\end{tabular}

\subsubsection{Effect on wax crystal morphology.}

Optical micrographs of crude oil without additive (neat) and after addition of 500ppm borate ester PPD formulation (doped) are shown in Fig. 4. Based on visual observation, the wax crystal density (crystal count) of micrographs of doped oil is lower, and the crystals are smaller in size. Wax crystallization in neat and doped oil can be compared quantitatively based on microscopic properties of wax crystals computed using image analysis software (Image $\mathbf{J}$ ) (Table 3). 

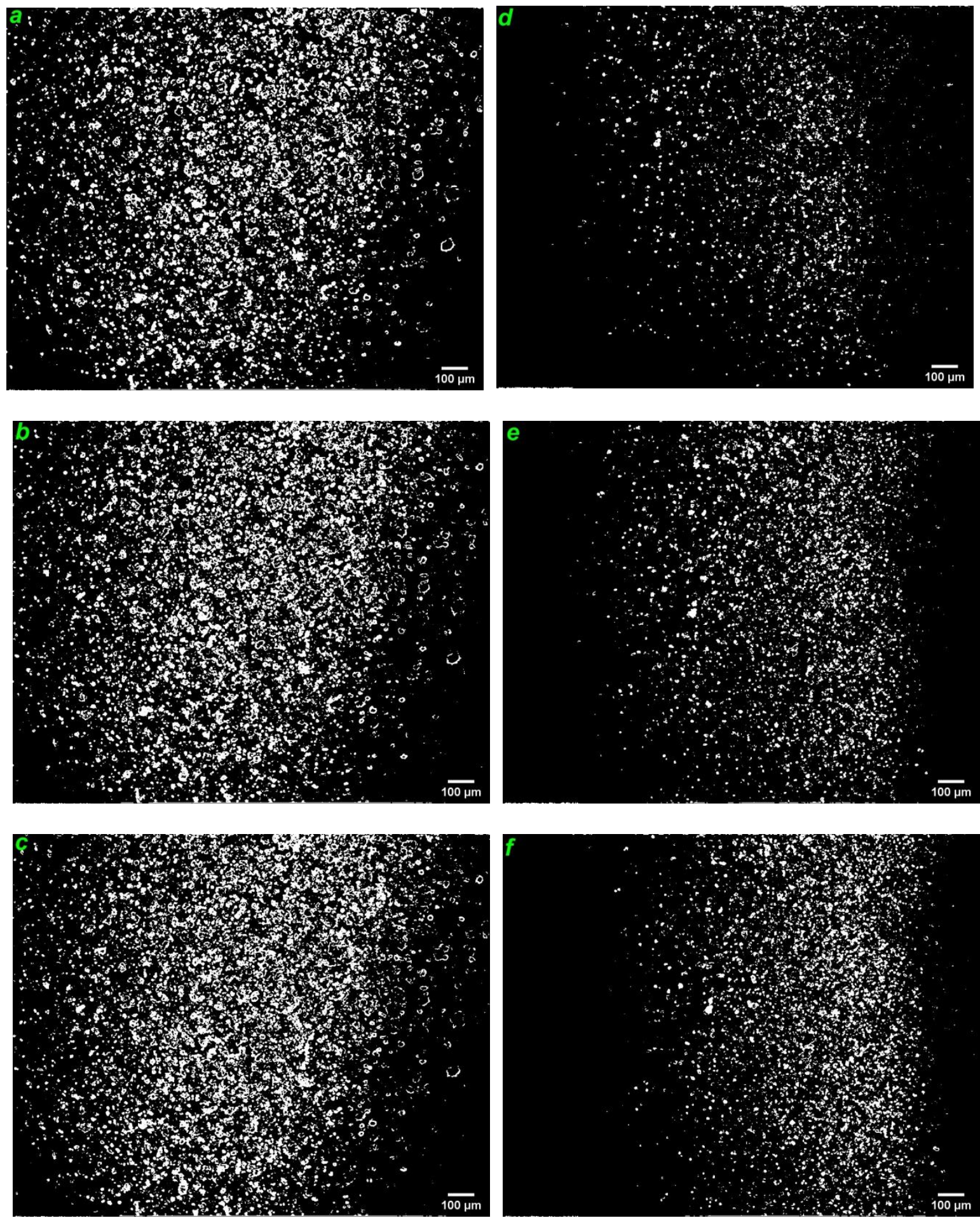

Figure 4. Cross polarized micrograph of neat crude oil at $20^{\circ} \mathrm{C}(a) ; 15^{\circ} \mathrm{C}(b) ; 10^{\circ} \mathrm{C}(c)$; and crude oil doped with 500 ppm borate ester at $20^{\circ} \mathrm{C}(d) ; 15^{\circ} \mathrm{C}(e) ; 10^{\circ} \mathrm{C}(f)$.

Aspect ratio (ratio of the major axis to the minor axis of the crystal) and circularity are crystal shape descriptors. Crystal roundness is the reciprocal of the aspect ratio. Perfectly round crystals have a minimum aspect ratio value of 1 . Higher aspect ratio values indicate that the wax crystals are more elongated and rod-like in shape. A maximum circularity value of 1.0 denotes a perfect circle. Circularity, dependent on wax crystal perimeter, reflects the degree of crystal shape regularity, with higher circularity values indicating greater crystal regularity. 
Table 3. Effect of additive on microscopic properties of wax crystals in crude oil.

\begin{tabular}{|c|c|c|c|c|c|}
\hline & & \multicolumn{4}{|c|}{ Microscopic parameters } \\
\hline & & Aspect & Solidity & Circularity & Boundary fractal \\
\hline Temp. & Sample & ratio & & & dimension \\
\hline \multirow[b]{2}{*}{$20^{\circ} \mathrm{C}$} & Neat oil & 1.65 & 0.85 & 0.814 & 1.55 \\
\hline & Doped oil & 1.63 & 0.89 & 0.870 & 1.20 \\
\hline \multirow[b]{2}{*}{$15^{\circ} \mathrm{C}$} & Neat oil & 1.69 & 0.84 & 0.811 & 1.58 \\
\hline & Doped oil & 1.64 & 0.86 & 0.850 & 1.39 \\
\hline \multirow[b]{2}{*}{$10^{\circ} \mathrm{C}$} & Neat oil & 1.72 & 0.83 & 0.798 & 1.61 \\
\hline & Doped oil & 1.71 & 0.85 & 0.830 & 1.47 \\
\hline
\end{tabular}

The microstructure of wax formed in the oil can be described quantitatively using the crystal solidity and boundary fractal dimension. Solidity is the ratio of the area of the crystal to its convex hull area. It is a measure of the evenness of the wax crystal surface. Decreasing solidity value signifies that wax crystal surfaces become increasingly ruffled and uneven while increasing boundary fractal dimension denotes increasing crystal roughness. It can be inferred from Table 3 that as the temperature of the oil decreases below the WAT, there is increasing crystal elongation and irregularity, the crystal surface becomes more ruffled and the edges rougher. Crystal roughness provides anchor points for crystal-crystal interlocking [41]. This temperature-induced change in morphology is due to increasing wax crystallization, crystal growth, and agglomeration with decreasing temperature. It favors the formation of strong wax networks in oil due to the higher tendency of rough elongated wax crystals to overlap and interlock, to the effect that oil flowability decreases as temperature drops. Relative to the neat oil, wax crystals in oil doped with the PPD are rounder in shape (lower aspect ratio), more regular, and have smoother edges and more even surfaces (Table 3).

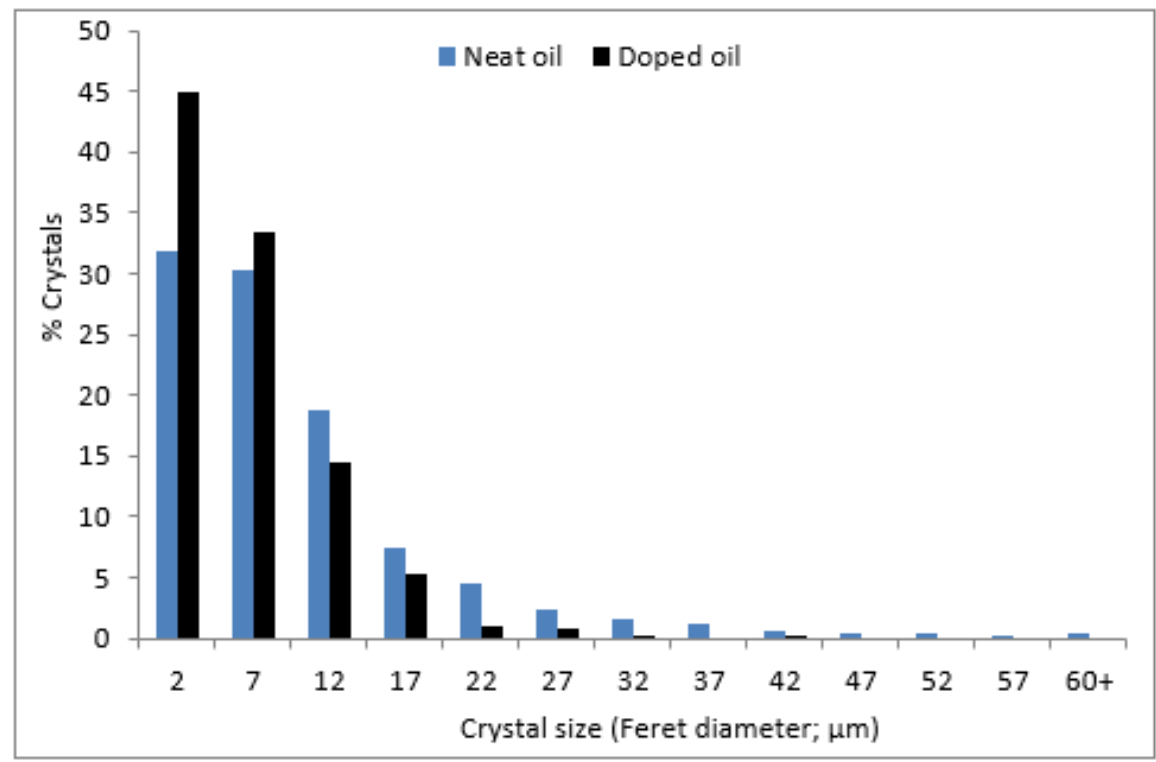

Figure 5. Effect of additive on wax crystal size distribution.

Figs. 5, 6, and 7 presents the size (crystal Feret diameter), roundness and solidity distributions, respectively, of wax crystals in neat and doped oil at $20^{\circ} \mathrm{C}$. Fig. 5 shows that the crystal size distribution shifts towards smaller crystals in oil containing the borate ester PPD. Crystals up to $60 \mu \mathrm{m}$ and above are formed in neat oil (without additive); however, in the doped oil, most of the wax crystals are $\leq 27 \mu \mathrm{m}$. This suggests that the borate ester PPD acts as an anti-agglomerate. The crystal roundness distribution is dominated by crystals with roundness 
values of $0.45(0.4-0.5), 0.65(0.6-0.7)$ and 0.95 (0.9 - 1.0 (Fig. 6). The proportion of crystals in each of these classes increases in the doped oil. The slight increase in crystals with a roundness value $<0.45$ in doped oil is probably due to the increasing number of very small crystals (Fig. 4). The solidity distribution also shifts in the presence of the additive, favoring crystals with perfect/ near-perfect solidity (0.9-1.0). This indicates an increasing proportion of even surface wax crystals (Fig. 7).

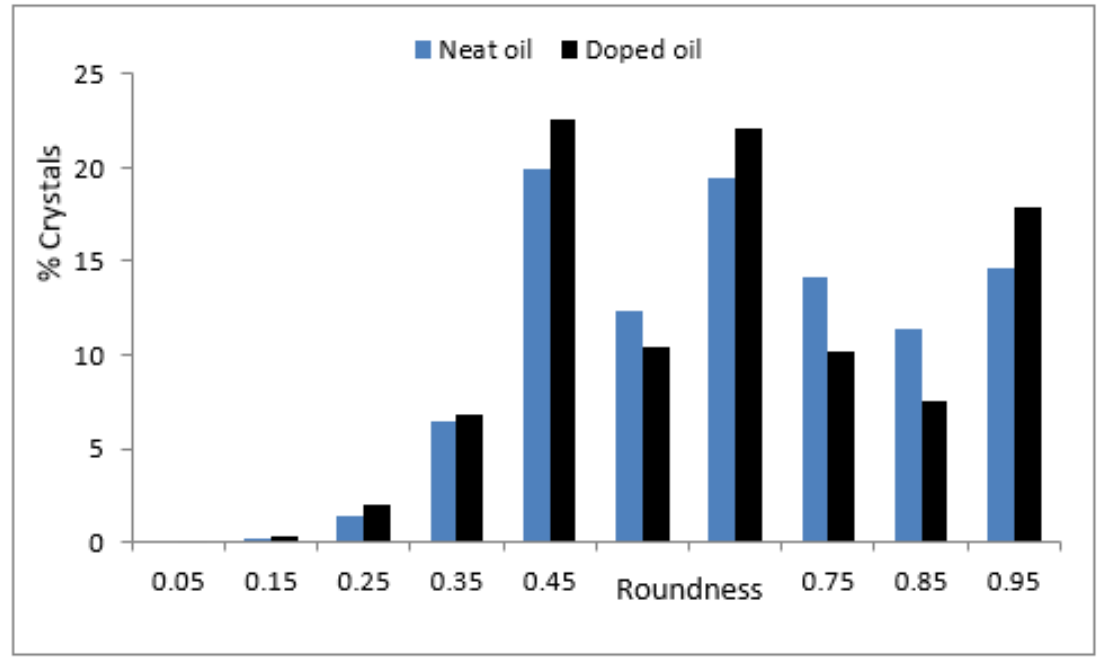

Figure 6. Effect of additive on wax crystal roundness distribution.

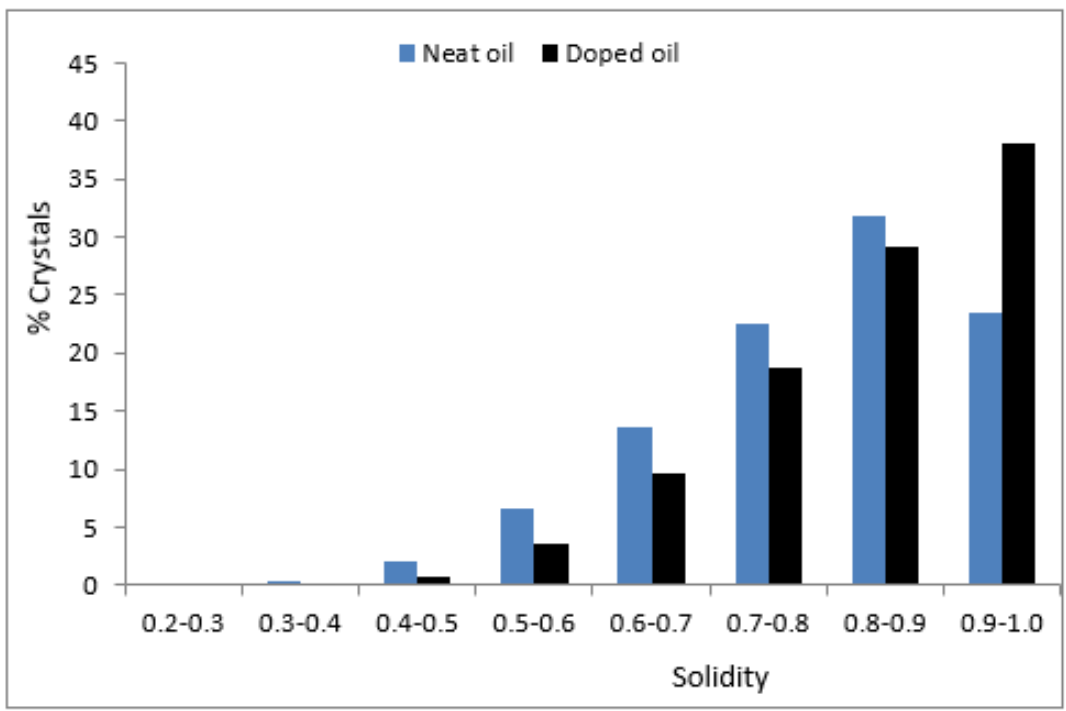

Figure 7. Effect of additive on wax crystal solidity distribution.

The changes in the morphology and microstructure of wax crystals in doped oil are unfavorable to wax crystal networking as rounder crystals are less prone to overlapping, and smooth crystal surfaces present fewer anchor points for crystal-crystal interlocking. Therefore, wax structures in doped oil are considerably weaker, explaining why the doped oil remains pourable at sub-zero temperatures while the neat oil gels at $21^{\circ} \mathrm{C}$ (Table 2).

The pour point depressant activity of the borate ester is likely due to its inhibitive effect on wax agglomeration in oil. The ability of the additive molecules to interact with wax in crude oil derives from the structural features of the alkylphenols, which constitute natural cashew nut shell liquid (mainly anacardic acid). The 15-carbon aliphatic chains of CNSL, similar to paraffin, facilitate interactions between additive molecules and crystallized wax probably via adsorption, whereas the benzene group and the polar carboxylic acid and borate groups, being 
dissimilar to paraffin, are detrimental to the wax formation process. The PPD molecules may adsorb onto incipient wax crystals via the aliphatic chains, while the carboxylic acid and borate groups $(\mathrm{C}-\mathrm{O}-\mathrm{B})$ attached to the benzene ring, which constitutes the polar segment, induce electrostatic repulsion between small wax crystals onto which the additive molecules are adsorbed [42]. Inter-particle repulsion hinders wax agglomeration, resulting in dispersion of waxes in oil. Wax dispersion improves oil flowability because the wax crystals cannot form large oil-occluding networks. The aromatic groups of the additive molecule may also facilitate wax solubilization in the oil and promote favorable interaction between waxes and asphaltenes and resins, which have an important influence on wax stability [43-45]. Based on the wax dispersal effect of the PPDs, the depreciation in PPD activity at treat rates above the optimal dosage is likely due to the high concentration of free (unadsorbed) additive molecules in the oil at these dosages. These excess additive molecules probably act as links between wax crystals that were hitherto dispersed in the oil, thereby promoting wax agglomeration.

\subsubsection{Effect on crude oil flow properties.}

Figs. 8-10 show the effect of the borate ester PPD on flow properties of the waxy crude oil at temperatures above and below the wax appearance temperature. Consistent with the observations made in the course of microscopic examination, the flowability of the oil decreases as temperature drops further below WAT. As the temperature of the neat oil decreases from $20^{\circ} \mathrm{C}$ to $10^{\circ} \mathrm{C}$, its shear stress rises rapidly with shear rate, and its viscosity increases (Figs. 8 \& 9).

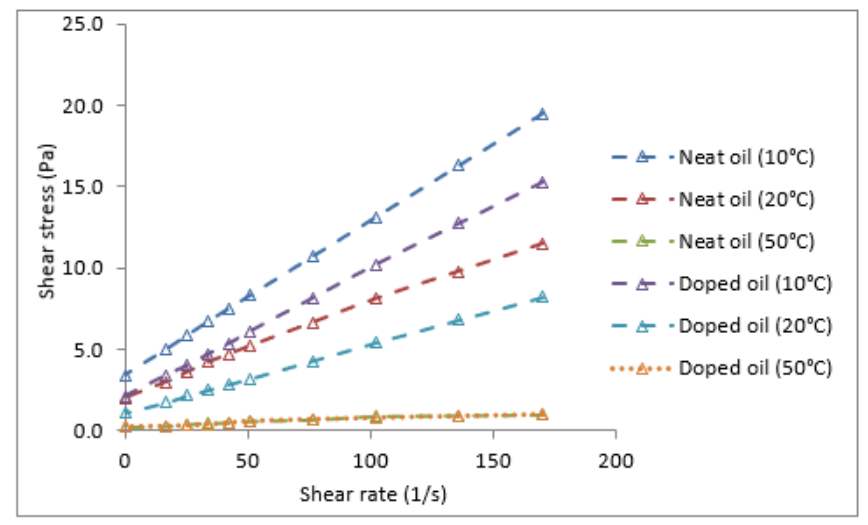

Figure 8 Effect of shear rate on shear stress of neat oil and oil doped with 500ppm borate ester.

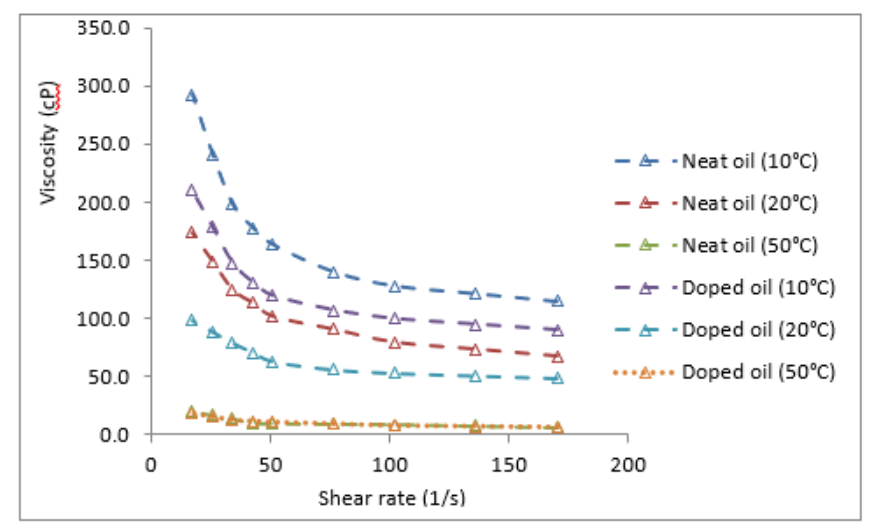

Figure 9. Effect of shear rate on viscosity of neat oil and oil doped with 500ppm borate ester. 


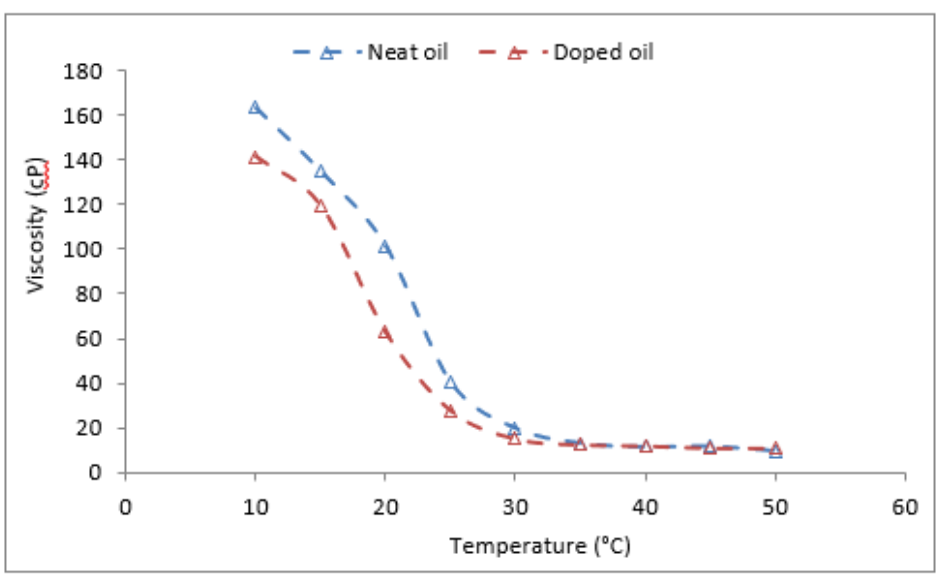

Figure 10. Effect of temperature on viscosity of neat oil and oil doped with 500ppm borate ester (shear rate: $\left.51 \mathrm{~s}^{-1}\right)$.

The increased resistance to flow exhibited by the oil is due to the increasing wax amount in oil and unfavorable changes observed in the morphology and microstructure of wax crystals with decreasing temperature (Table 3). Upon doping with 500ppm of borate ester additive, oil shear stress (obtained as an average across the experimental shear rate) was reduced by $37.3 \%$ and $27.6 \%$ at $20^{\circ} \mathrm{C}$ and $10^{\circ} \mathrm{C}$, respectively. Similarly, the oil's viscosity was reduced by $34.6 \%$ and $24.6 \%$, indicating lower internal friction in doped oil. This is attributable to the morphological and micro-structural changes in wax crystals in doped oil [46]. This is because the smaller wax crystals with smooth edges and even surfaces in the doped oil likely experience lower frictional resistance within the flowing oil compared to larger, rough crystals.

Above WAT $\left(50^{\circ} \mathrm{C}\right)$, the shear rate-shear stress curve, as well as the shear rate-viscosity curve of the doped oil, is superimposed on the neat oil. The borate ester PPD has no effect on the flow behavior of the oil in the absence of crystallized wax. This is also evident in the plot of viscosity against oil temperature at a constant shear rate $\left(51 \mathrm{~s}^{-1}\right)$ in the temperature region above WAT (from $50^{\circ} \mathrm{C}$ to about $35^{\circ} \mathrm{C}$ ) (Fig. 10). The point of divergence in the viscositytemperature curve of neat and doped oil approximates the wax appearance temperature of the oil $\left(33.6^{\circ} \mathrm{C}\right)$ determined by cross-polarized microscopy. The inflection in the curves, characterized by a rapid increase in viscosity, occurs as wax crystallizes upon oil attaining its WAT, with decreasing oil temperature. In the temperature region below the WAT, the viscosity-temperature curve of doped oil lags behind the neat oil. The increment in oil viscosity with temperature reduction is smaller. These observations indicate improved low-temperature flowability.

\section{Conclusions}

Borate ester of natural cashew nut shell liquid was prepared and evaluated as pour point depressant and low-temperature flow improver for waxy crude oil. The low-cost additive showed good pour point depressant activity, which was dependent on dosage. The pour point depressant and flow improvement effect of the CNSL-borate ester formulation was linked to the changes in morphology and micro-structure of waxes formed in doped crude oil. Microscopic study of crude oil under static cooling, with and without the additive, revealed that the microscopic properties of waxes formed in doped oil were changed, evidenced by a decrease in crystal Feret diameter, aspect ratio, and boundary fractal dimension, and an increase in crystal circularity and solidity, which signified that crystals in doped oil were smaller, 
rounder, regular structures with smooth, even surfaces. These morphological changes are unfavorable to the formation of strong wax networks in oil, such that the oil can still pour at low temperatures. It also reduces the internal frictional resistance in cold oil for improved flowability. The performance of the additive is thought to be due to its inhibitive effect on wax agglomeration and increased solubilization of waxes in sheared oil by interactions of additive molecules with oil components via the aliphatic chains aromatic rings, and polar carboxylic acid and borate groups.

\section{Funding}

This research received no external funding.

\section{Acknowledgments}

The authors would like to thank Shell Petroleum Development Company (SPDC), Port Harcourt, for providing the laboratory facilities for this work.

\section{Conflicts of Interest}

The authors declare no conflict of interest.

\section{References}

1. Ajienka, J.A.; Ikoku, C.U. Waxy Crude Oil Handling in Nigeria: Practices, Problems, and Prospects. Energy Sources 1990, 12, 463-478, https://doi.org/10.1080/00908319008960219.

2. Merino-Garcia, D.; Correra, S. Cold Flow: A Review of a Technology to Avoid Wax Deposition. Petroleum Science and Technology 2008, 26, 446-459, https://doi.org/10.1080/10916460600809741.

3. Zhang, J.; Yu, B.; Li, H.; Huang, Q. Advances in rheology and flow assurance studies of waxy crude. Petroleum Science 2013, 10, 538-547, https://doi.org/10.1007/s12182-013-0305-2.

4. Adeyanju, O.; Oyekunle, L. An Experimental Study of Rheological Properties of Nigerian Waxy Crude Oil. Petroleum Science and Technology 2012, 30, 1102-1111, https://doi.org/10.1080/10916466.2010.498717.

5. Mahto, V.; Verma, D.; Singh, H. Kinetic study of wax deposition in the flow lines due to Indian crude oil. International Journal of Oil, Gas and Coal Technology 2015, 10, 293-305, https://dx.doi.org/10.1504/IJOGCT.2015.071506.

6. Sanjay, M.; Simanta, B.; Kulwant, S. Paraffin Problems in Crude Oil Production And Transportation: A Review. SPE Production \& Facilities 1995, 10, 50-54, https://doi.org/10.2118/28181-PA.

7. Fouad F.; Hernandez, O.; Sturgis, R.; Meng, W. Evaluation of Pipeline Configuration with Active Heating for Export of Waxy Crude Oil'. SPE-90054-MS. Paper Presented at SPE Annual Technical Conference and Exhibition. 26-29 September 2004. Houston, Texas 2004, https://doi.org/10.2118/90054-MS.

8. Li, S.; Huang, Q.; Fan, K.; Zhao, D.; Lv, Z. Transportation technology with pour point depressant and wax deposition in a crude oil pipeline. Petroleum Science and Technology 2016, 34, 1240-1247, https://doi.org/10.1080/10916466.2015.1050504.

9. de Oliveira, M.C.K.; Teixeira, A.; Vieira, L.C.; de Carvalho, R.M.; de Carvalho, A.B.M.; do Couto, B.C. Flow Assurance Study for Waxy Crude Oils. Energy \& Fuels 2012, 26, 2688-2695, https://doi.org/10.1021/ef201407j.

10. Ridzuan, N.; Subramanie, P.; Uyop, M.F. Effect of pour point depressant (PPD) and the nanoparticles on the wax deposition, viscosity and shear stress for Malaysian crude oil. Petroleum Science and Technology 2020, 38, 929-935, https://doi.org/10.1080/10916466.2020.1730892.

11. Hao, L.Z.; Al-Salim, H.S.; Ridzuan, N. A Review of the mechanism and Role of Wax Inhibitors in the Wax Deposition and Precipitation. Pertanika Journal of Science and Technology 2019, 27, 499-526.

12. Zhang, J.; Wu, C.; Li, W.; Wang, Y.; Han, Z. Study on performance mechanism of pour point depressants with differential scanning calorimeter and X-ray diffraction methods https://doi.org/10.1016/S0016-2361(03)00028-0.

13. Li, N.; Mao, G.; Shi, X.; Tian, S.; Liu, Y. Advances in the research of polymeric pour point depressant for waxy crude oil. Journal of Dispersion Science and Technology 2018, 39, 1165-1171, https://doi.org/10.1080/01932691.2017.1385484. 
14. Akinyemi, O.P.; Udonne, J.D.; Oyedeko, K.F. Experimental Study of Utilization of Plant Seed Oil as Pour Point Depressant for Nigerian Waxy Crude Oil. International Journal of Science and Engineering Research 2018, 9, 205-209.

15. Akinyemi, O.P.; Udonne, J.D.; Oyedeko, K.F. Study of effects of blend of plant seed oils on wax deposition tendencies of Nigerian waxy crude oil. Journal of Petroleum Science and Engineering 2018, 161, 551-558, https://doi.org/10.1016/j.petrol.2017.12.017.

16. Azeem, A.; Kumar, R.; Pal, B.; Naiya, T.K. Use of novel pour point depressant synthesized from vegetable oil for waxy crude oil. Petroleum Science and Technology 2020, 38, 185-193, https://doi.org/10.1080/10916466.2019.1697291.

17. Banerjee, S.; Kumar, R.; Mandal, A.; Naiya, T.K. Effect of Natural and Synthetic Surfactant on the Rheology of Light Crude Oil. Petroleum Science and Technology 2015, 33, 1516-1525, https://doi.org/10.1080/10916466.2015.1079539.

18. Chen, G.; Tang, Y.; Zhang, J. Synthesis and application of polyaminoamide as new paraffin inhibitor from vegetable oil. Chemistry Central Journal 2011, 5, 82-84, https://doi.org/10.1186/1752-153X-5-82.

19. Deng, Q.; Bai, Y.; Gu, X.; Chen, G.; Zhang, Z. Synthesis of Poly-Hydrazide from Canola Oil and Use as a Flow Improver for Crude Oil. Advances in Engineering Research 2016, 103, 281-285, https://doi.org/10.2991/ICMEA-16.2016.46.

20. Ragunathan, T.; Husin, H.; Wood, C.D. Effects of Crude Palm Oil and Crude Palm Kernel Oil Upon Wax Inhibition. ACS Omega 2020, 5, 19342-19349, https://doi.org/10.1021/acsomega.0c00753.

21. Huyen, Q.T.M.; Khanh, N.V. Synthesis of Crude Oil Pour Point Depressants via Polycondensation of Cashew Nut Shell Liquid. Petrovietnam 2014, 6, 48-52.

22. Huyen, Q.T.M.; Chau N.G.M.; Tuan, N.B.H.; Thoa, D.T.K.; Khanh, N.V. Synthesis routes for potential pour point depressants from cashew nut shell liquids. Journal of Catalysis and Adsorption 2012, 1, 176-183.

23. Eke, W.I.; Achugasim, O.; Ofordile, S.E.; Ajienka, J.; Akaranta, O. Performance Evaluation of Cashew Nut Shell Liquid CNSL as Flow Improver for Waxy Crude Oils. SPE-198721-MS. Paper Presented at SPE Nigeria Annual International Conference and Exhibition. Lagos, Nigeria, 5-7 August 2019, https://doi.org/10.2118/198721-MS.

24. Eke, W.I.; Kyei, S.K.; Ajienka, J.; Akaranta, O. Effect of bio-based flow improver on the microscopic and low-temperature flow properties of waxy crude oil. Journal of Petroleum Exploration and Production 2021, 11, 711-724, https://doi.org/10.1007/s13202-020-01078-X.

25. Philip, J.Y.N.; Da Cruz Francisco, J.; Dey, E.S.; Buchweishaija, J.; Mkayula, L.L.; Ye, L. Isolation of Anacardic Acid from Natural Cashew Nut Shell Liquid (CNSL) Using Supercritical Carbon Dioxide. Journal of Agricultural and Food Chemistry 2008, 56, 9350-9354, https://doi.org/10.1021/jf801532a.

26. Tyman, J.H. Determination of the component phenols in natural and technical cashew nut-shell liquid by gasliquid chromatography. Analytical Chemistry 1976, 48, 30-34, https://doi.org/10.1021/ac60365a049.

27. Eke, W.I.; Achugasim, O.; Ajienka, J.; Akaranta, O. Glycerol-modified cashew nut shell liquid as ecofriendly flow improvers for waxy crude oil. Petroleum Science and Technology 2021, 39, 101-114, https://doi.org/10.1080/10916466.2020.1849284.

28. Eke, W.I.; Kyei, S.K.; Achugasim, O.; Ajienka, J.A.; Akaranta, O. Pour point depression and flow improvement of waxy crude oil using polyethylene glycol esters of cashew nut shell liquid. Applied Petrochemical Research 2021, https://doi.org/10.1007/s13203-021-00271-1.

29. Eke, W.I.; Achugasim, O.; Ofordile, S.E.; Ajienka, J.; Akaranta, O. Cashew Nut Shell Liquid Ethylene Glycol Derivatives as Pour Point Depressants for Waxy Crude Oil. Petroleum and Coal 2020, 63, 224-233.

30. Carbognani, L.; Orea, M.; Fonseca, M. Complex Nature of Separated Solid Phases from Crude Oils. Energy \& Fuels 1999, 13, 351-358, https://doi.org/10.1021/ef9801975.

31. García, M.d.C. Crude Oil Wax Crystallization. The Effect of Heavy n-Paraffins and Flocculated Asphaltenes. Energy \& Fuels 2000, 14, 1043-1048, https://doi.org/10.1021/ef0000330.

32. Eke, W.I.; Achugasim, O.; Ofordile, S.E.; Ajienka, J.; Akaranta, O. Influence of Heavy Organics Composition on Wax Properties and Flow Behavior of Waxy Crude Oils. Chemical Science International Journal 2019, 27, 1-12, https://doi.org/10.9734/CSJI/2019/v27i230109.

33. Senra, M.; Panacharoensawad, E.; Kraiwattanawong, K.; Singh, P.; Fogler, H.S. Role of n-Alkane Polydispersity on the Crystallization of n-Alkanes from Solution. Energy Fuels 2008, 22, 545-555, https://doi.org/10.1021/ef700490k.

34. Paso, K.G.; Fogler, H.S. Bulk Stabilization in Wax Deposition Systems. Energy \& Fuels 2004, 18, 10051013, https://doi.org/10.1021/ef034105+.

35. Bai, C.; Zhang, J. Effect of Carbon Number Distribution of Wax on the Yield Stress of Waxy Oil Gels. Industrial \& Engineering Chemistry Research 2013, 52, 2732-2739, https://doi.org/10.1021/ie303371c.

36. Gandhi, D.T.; Patel, M.; Dholakiya, B. Studies on effect of various solvents on extraction of cashew nut shell liquid (CNSL) and isolation of major phenolic constituents from extracted CNSL. Scholars Research Library 2012, 2,135-142,

37. Gedam, P.H.; Sampathkumaran, P.S. Cashew nut shell liquid: Extraction, chemistry and applications. Progress in Organic Coatings 1986, 14, 115-157, https://doi.org/10.1016/0033-0655(86)80009-7. 
38. Tyman, J.H.P.; Johnson, R.A.; Muir, M.; Rokhgar, R. The extraction of natural cashew nut-shell liquid from the cashew nut (Anacardium occidentale). Journal of the American Oil Chemists' Society 1989, 66, 553-557, https://doi.org/10.1007/BF02885447.

39. He, Z.; Xiong, L.; Xie, F.; Shen, M.; Han, S.; Hu, J.; Xu, W. Tribological and antioxidation properties study of two N-containing borate ester derivatives as additive in rapeseed oil. PLOS ONE 2018, 13, https://doi.org//10.1371/journal.pone.0207267.

40. Yang, G.; Zhao, J.; Cui, L.; Song, S.; Zhang, S.; Yu, L.; Zhang, P. Tribological characteristic and mechanism analysis of borate ester as a lubricant additive in different base oils. RSC Advances 2017, 7, 7944-7953, https://doi.org/10.1039/C6RA26896J.

41. Paso, K.; Senra, M.; Yi, Y.; Sastry, A.M.; Fogler, H.S. Paraffin Polydispersity Facilitates Mechanical Gelation. Industrial \& Engineering Chemistry Research 2005, 44, 7242-7254, https://doi.org/10.1021/ie050325u.

42. Yao, B.; Chen, W.; Li, C.; Yang, F.; Sun, G.; Wang, G.; Xu, H. Polar asphaltenes facilitate the flow improving performance of polyethylene-vinyl acetate. Fuel Processing Technology 2020, 207, https://doi.org/10.1016/j.fuproc.2020.106481.

43. Al-Sabagh, A.M.; Noor El-Din, M.R.; Morsi, R.E.; Elsabee, M.Z. Styrene-maleic anhydride copolymer esters as flow improvers of waxy crude oil. Journal of Petroleum Science and Engineering 2009, 65, 139-146, https://doi.org/10.1016/j.petrol.2008.12.022.

44. Palermo, L.C.M.; Souza, N.F.; Louzada, H.F.; Bezerra, M.C.M.; Ferreira, L.S.; Lucas, E.F. Development of Multifunctional Formulations for Inhibition of Waxes and Asphaltenes Deposition. Brazilian Journal of Petroleum and Gas 2013, 7, 181-192, http://dx.doi.org/10.5419/bjpg2013-0015.

45. Venkatesan, R.; Östlund, J.-A.; Chawla, H.; Wattana, P.; Nydén, M.; Fogler, H.S. The Effect of Asphaltenes on the Gelation of Waxy Oils. Energy \& Fuels 2003, 17, 1630-1640, https://doi.org/10.1021/ef034013k.

46. Yi, S.; Zhang, J. Relationship between Waxy Crude Oil Composition and Change in the Morphology and Structure of Wax Crystals Induced by Pour-Point-Depressant Beneficiation. Energy \& Fuels 2011, 25, 16861696, https://doi.org/10.1021/ef200059p. 